\title{
A RELAÇÃO ENTRE DESMOTIVAÇÃO E O PROCESSO ENSINO-APRENDIZAGEM
}

\author{
Teresinha de Fátima Souto Almeida ${ }^{1}$ Jerônimo Sartori ${ }^{2}$ \\ ${ }^{1}$ Especialista em Educação: Interdisciplinaridade e Transversalidade, Universidade Federal do Pampa. \\ souto.al@hotmail.com. \\ ${ }^{2}$ Professor Adjunto da Universidade da Fronteira Sul. Professor do curso de Especialista em Educação: \\ Interdisciplinaridade e Transversalidade, Universidade Federal do Pampa.
}

jetori55@yahoo.com.br.

\section{RESUMO}

Este artigo busca analisar a influência da desmotivação no processo ensino-aprendizagem, abordando a questão da interdisciplinaridade, como fator de integração no processo de construção do conhecimento; levantando indicadores sobre o que leva professores e alunos a se sentirem desmotivados. Para a análise adotam-se os pressupostos do ensino-aprendizagem, entendendo a educação no seu aspecto interdisciplinar e sua relação com a desmotivação. Para estabelecer um contraponto com o referencial teórico analisado, foi realizado um diagnóstico sobre o contexto escolar, o qual fora sistematizado após a análise sob um olhar crítico e reflexivo, identificando algumas alternativas de soluções para o problema da desmotivação no Ensino Fundamental. Segundo o diagnóstico ficou evidente que a desmotivação leva o aluno à repetência e à evasão escolar, no entanto, acredita-se ser possível reverter o quadro trabalhando na perspectiva da interdisciplinaridade, empregando as tecnologias da comunicação e investindo na formação continuada dos professores para que se reflita na possibilidade de mudar a prática pedagógica, tendo um olhar mais atento às necessidades dos alunos do ensino noturno.

Palavras-Chave: Desmotivação, Ensino noturno, Prática pedagógica, Ensino-aprendizagem.

\section{ABSTRACT}

This paper analyzes the influence of the lack of motivation in the teaching - learning process, addressing the issue of interdisciplinarity as a factor of integration in the process of knowledge construction. A survey of the leading indicators on teachers and students' discouragement was conducted. For the analysis it was adopted the assumptions of the teaching and learning process, understanding education in its interdisciplinary aspects and its relation to lack of motivation. To establish a comparison with the theoretical analysis, a diagnosis was made on the school context, which was systematized after a critical and reflexive analysis, identifying some alternative solutions to the problem of lack of motivation in elementary schools. According to the diagnosis it was evident that the lack of motivation leads to failing and dropping out. However, it was concluded that it is possible to overturn the situation through a work in an interdisciplinary perspective using the communication technologies as well as investing in teacher training aiming to think over changing in the pedagogical practice, taking a closer look at the needs of the evening course students. 
Keywords: Lack of motivation, Evening course, Pedagogical practice, Teaching and learning. INTRODUÇÃO

É recorrente a fala nas escolas de que os alunos estão desmotivados, de que eles não têm interesse nos estudos, não participam das aulas, não realizam as atividades em classe e nem extraclasse. Frente a esta situação fica um questionamento: o que leva o educando a desmotivarse para os estudos? Não se trata, nesta investigação, de buscar uma "receita" para motivar os estudantes em sala de aula - na escola, mas de entender algumas das razões que retiram o aluno do foco dos estudos.

Para os professores da educação básica, o ato de planejar se reveste de muita expectativa, pois, há no horizonte uma perspectiva investida de intencionalidade, do vir-a-ser. No planejamento os docentes colocam suas metas, suas utopias, seus desejos, no sentido de que os estudantes construam novos conhecimentos, assimilem e acomodem novos conceitos, novos saberes que se tornem significativos para a vida.

Ainda no ato de planejar, o educador busca indicar atividades e metodologias diferenciadas, para tornar suas aulas mais atraentes, dinâmicas e motivadoras, no sentido de que os alunos sintam-se motivados a aprender. Mas, não é raro o educador adentrar numa sala de aula e deparar-se com os educandos que gostariam de estar em qualquer lugar, menos na escola, ou seja, num lugar diferente da sala de aula.

Tal situação constitui indicativo de que a desmotivação para o estudo é realidade entre os alunos da maioria das escolas brasileiras, por isso, é indispensável que se reflita sobre a problemática em questão. Cabe destacar que a desmotivação vem sendo observada não só pelos docentes, muitos dos pais já perceberam que seus filhos, revelam por meio de suas atitudes, um certo desleixo em relação às atividades que são patrocinadas pela escola.

No âmbito escolar, determinados alunos apresentam dificuldades em interagir com o grupo na realização das atividades, outros apresentam resistência em envolver-se com as ações que visam a construção de conhecimentos, isolando-se dos demais colegas e dos professores, negando-se a participar das tarefas propostas, não apresentando interesse em realizar aquilo que se refere à sua própria aprendizagem. Tais indicadores evidenciam situações que demonstram que o educando se encontra desmotivado.

Com isso, o professor precisa ficar atento ao comportamento dos alunos, visto que a desmotivação pode partir de adolescentes e jovens mais agitados, bem como daqueles desligados e inquietos ou, ainda, dos sujeitos que são considerados "apáticos". Nesse sentido, o professor necessita preocupar-se com o ambiente escolar, em especial com a sala de aula, com a organização e o desenvolvimento das atividades, com a relação professor-aluno e com o processo avaliativo, para não desmotivar ainda mais o estudante.

Nesse sentido, acredita-se no pressuposto de que a desmotivação tem implicações negativas no processo ensino-aprendizagem; todavia, entre as causas da ausência de motivação, o planejamento e o desenvolvimento das aulas por parte do professor são fatores determinantes. 0 educador necessita fundamentar sua ação docente de acordo com as necessidades dos estudantes, levando em consideração sempre as angústias e as ansiedades que se entrecruzam na vida do aluno naquele dado momento.

Cabe destacar que este artigo aborda o tema desmotivação, focando para "a influência da desmotivação no processo ensino-aprendizagem", no intuito de investigar algumas das causas que levam à desmotivação dos adolescentes e jovens, bem como quais as consequências de tal 
influência no ato de ensinar e de aprender. Para tanto, empregou-se como metodologia o estudo bibliográfico com base no levantamento teórico e a pesquisa de campo para levantar o diagnóstico da comunidade escolar, considerando-se o tema abordado.

No referencial teórico, partiu-se do entendimento sobre interdisciplinaridade como proposta e atitude de trabalho em sala de aula, seguido de uma análise sobre a desmotivação de professores e de alunos no desenvolvimento do processo educativo, envolvendo os pressupostos relativos à educação, ao ensino e à aprendizagem, considerando que a atuação interdisciplinar pode auxiliar na superação de questões relacionadas à desmotivação. Nos pressupostos relacionados ao ensino e à aprendizagem refletiu-se sobre a perspectiva metodológica desenvolvida, fazendo um contraponto com o que foi levantado no diagnóstico escolar produzido por meio de questionários.

Por meio dos dados coletados ficou evidente que existem preocupações por parte dos professores em relação à desmotivação evidenciada pelos alunos o que, por consequência acaba desmotivando também os próprios professores. No entanto, percebe-se também que existe necessidade de mudanças, principalmente na questão metodológica que é adotada no desenvolvimento das aulas, na maioria das vezes, preterizando a prática interdisciplinar, a qual ainda é muito pouco adotada no cotidiano escolar.

\section{METODOLOGIA}

A pesquisa consiste num processo que busca informações sobre uma determinada problemática na perspectiva de analisá-la, utilizando o método científico com o propósito de avançar no conhecimento da temática de investigação. Desse modo, tendo em vista a busca de respostas ao problema indicado, é necessário recorrer à formulação de uma metodologia que se adéque aos procedimentos da pesquisa científica.

A metodologia descreve de modo detalhado o processo de como o método adotado em uma pesquisa é concretizado na prática. Mais, a metodologia indica a forma como uma investigação é desenvolvida, descreve o local, os sujeitos abordados, o espaço geográfico, a situação social, econômica, política, cultural, educacional, enfim, busca as informações de acordo com os objetivos e a definição da problemática.

Esta pesquisa utilizou como metodologia a pesquisa bibliográfica e a pesquisa de campo. A pesquisa bibliográfica é o passo inicial na construção efetiva de uma listagem de bibliografias acerca do tema apontado, envolvendo a leitura, a análise e a interpretação de livros, periódicos, textos legais, artigos, etc. De acordo com Ruiz (1991), a pesquisa bibliográfica consiste na exploração do manancial de produção científica que está guardada em livros e artigos produzidos sobre determinado assunto. Ainda, como suporte teórico para esse estudo, priorizou-se o uso de teorias de autores que contemplam o tema escolhido, tais como: Caporaline (1997), Carvalho (1998), Fazenda (1994), Melo (2001), Komesu (2004), Piaget (1973), Vygotsky (1998) e outros.

Para tratar deste tema na educação escolar, fez-se necessário articular a pesquisa bibliográfica com a de campo, na perspectiva de uma análise qualitativa. Neste trabalho realizouse um levantamento de dados por meio da aplicação de questionários, que tiveram como objetivo investigar as causas que levam à desmotivação dos adolescentes e jovens, bem como as conseqüências de sua influência no processo ensino-aprendizagem. 
A coleta dos dados foi desenvolvida nos turnos diurno e noturno de uma Escola Estadual situada na periferia do município de São Gabriel, a qual atende aproximadamente seiscentos (600) alunos distribuídos em três (3) turnos. O levantamento de dados por meio de questionários teve como objetivo realizar um detalhado diagnóstico da realidade escolar, considerando os segmentos alunos e professores das séries finais do Ensino Fundamental no ano de 2010.

Participaram da pesquisa trinta alunos e doze professores, o instrumento de pesquisa foi aplicado durante o horário normal de aulas. A partir da aplicação dos questionários iniciaram-se as transcrições, bem como a análise da percepção dos alunos pesquisados, o que possibilitou a elaboração final deste artigo, cuja reflexão está embasada na teoria de autores que tratam sobre a desmotivação no processo ensino-aprendizagem.

A discussão traz dados sobre as preocupações com os principais fatores que contribuem para que ocorra a desmotivação entre os educandos das séries finais do Ensino Fundamental, buscando compreender este fenômeno.

O referencial teórico, fruto da pesquisa bibliográfica, não é apenas uma síntese do conhecimento acumulado sobre o tema. Mesmo cumprindo esta importante função, serve inicialmente para identificar o atual estágio do conhecimento sobre o assunto em questão, mas é também essencial para que se possa definir melhor o problema de pesquisa, analisar de forma coerente e apontar algumas das possíveis soluções.

\section{TECENDO ALGUMAS IDEIAS SOBRE INTERDISCIPLINARIDADE}

A aprendizagem e o desenvolvimento do pensamento acontecem por meio da interação social, indicando que a aprendizagem representa a reestruturação dos saberes e dos comportamentos evidenciados pelos estudantes. Por isso, são fundamentais as atividades que exigem troca de opinião e cooperação mútua, o que favorece a reflexão e a reconstrução dos conhecimentos historicamente produzidos pelo ser humano. Ao falar da interdisciplinaridade não se quer passar a ideia de eliminação das disciplinas, mas de torná-las comunicativas e/ou interligadas entre si, ainda, de entendê-las como processos históricos e culturais, indicando a necessidade da sua atualização no que se refere às práticas pedagógicas empregadas para que ocorra o processo de ensino-aprendizagem.

Embora não seja possível a criação de uma única e restrita teoria da interdisciplinaridade, é fundamental que se oriente para o movimento pelo qual os estudiosos da temática da interdisciplinaridade têm convergido nas últimas três décadas (FAZENDA, 1994, p. 14).

O surgimento do movimento da interdisciplinaridade deu-se como tentativa para elucidar e classificar algumas temáticas das propostas educacionais que começavam a aparecer em meados da década de 60, principalmente, na França e na Itália. Tal preocupação emerge do compromisso de alguns professores, em certas universidades, que buscavam por meio de suas lutas e sacrifícios o rompimento com a denominada educação por "migalhas", também chamada de fragmentada e descontextualizada.

O ensino formal estruturado e institucionalizado no formato de disciplinas e conteúdos delimitados, na maioria das vezes, nada tem a ver com o mundo real do estudante, o que torna a sua aprendizagem algo desinteressante e artificial. Cabe ressaltar que a estrutura curricular 
disciplinar rígida e hierarquizada no sistema escolar, muitas vezes, torna difícil concretizar as iniciativas que visam práticas interdisciplinares. Em razão disso, é que se amplia cada vez mais a necessidade da compreensão dos conhecimentos, que auxiliam para o entendimento dos sentidos existenciais e intelectuais dos sujeitos. A busca por tais sentidos requer respeito aos princípios básicos da organicidade dos conhecimentos e da compreensão destes em sua totalidade.

Gurdof, de acordo com Fazenda (1994), foi um dos principais precursores do movimento em prol da interdisciplinaridade, o qual tinha no seu horizonte a totalidade como categoria de reflexão. No Brasil a primeira produção significativa sobre o tema interdisciplinaridade foi de Hilton Japiassú (1976); naquele período, o autor já apresentava questionamentos significativos acerca da temática interdisciplinaridade e seus conceitos; já promovia reflexões sobre algumas estratégias interdisciplinares, considerando algumas experiências realizadas naquela época.

Em se tratando de educação, a interdisciplinaridade se tornou a palavra de ordem do final do século XX. Começa ai as reações às concepções unilaterais de educação, mesmo com a adesão de poucos professores já se vislumbravam as possibilidades de atuarem nesta perspectiva. De acordo com Fazendo (1994), os professores conservam a sua forma própria de ser educador, de ser pesquisador, de dar aulas num paradigma de patriarcado que enquadra, rotula, modula, cerceia, limita, fato que evidencia que a mudança é possível, mas a passos lentos.

A interdisciplinaridade situa-se como eixo articulador entre os princípios pedagógicos que estruturam as áreas do conhecimento. A construção de uma didática interdisciplinar embasa-se na possibilidade da efetivação de trocas intersubjetivas. De acordo com Japiassu "a interdisciplinaridade caracteriza-se pela intensidade das trocas entre os especialistas e pelo grau de interação real das disciplinas no interior de um mesmo projeto de pesquisa" (1976, p. 74). Nesse sentido, o papel e a postura do profissional da educação que procura promover qualquer tipo de intervenção, tendo em vista a construção de uma didática transformadora ou interdisciplinar, deverá promover essa possibilidade de trocas, estimulando o autoconhecimento sobre a própria prática de cada sujeito, contribuindo para a ampliação da leitura de aspectos da realidade, ainda não desvendados nas práticas cotidianas da escola.

No contexto escolar, primeiro é necessário que haja a compreensão de que as disciplinas escolares resultam de recortes e seleções arbitrárias, pois, foram construídas ao longo da história, além de expressões de interesses e relações de poder que ressaltam, ocultam ou negam saberes para que a interdisciplinaridade possa ser concretizada. Cabe, desse modo, ressaltar que nem todos os campos do saber são privilegiados em sua representação como disciplina escolar, por não serem considerados úteis para resolver situações-problema do cotidiano. Tal compreensão é histórica, haja vista a permanente visão de negar a teoria e de supervalorizar a prática.

A sala de aula é o lugar em que a interdisciplinaridade habita, bem como da maneira como as disciplinas são abordadas e inseridas no currículo escolar, o que se constitui em indicadores de uma ação pedagógica que propicia ao aluno a construção de um conhecimento fragmentado ou significativo, observando a compreensão dos fenômenos naturais, sociais e culturais, em que a ordem e o rigor são travestidos de uma nova ordem e de um novo rigor. A despeito disso, a temática da interdisciplinaridade é entendida como uma maneira de trabalhar em sala de aula, em que o docente propõe um tema com abordagens que transitam por diferentes disciplinas. Portanto, é preciso compreender os elementos de ligação entre as diferentes áreas de conhecimento, unindo-se para planejar e desenvolver algo inovador, que favoreça o resgate da totalidade do saber, possibilitando que se ultrapasse o pensar e o fazer de modo fragmentado.

Desse modo, na perspectiva de uma prática pedagógica interdisciplinar, reside o esforço conjunto de professores de diferentes disciplinas do currículo escolar na busca de um eixo comum em torno do qual se articulam elementos teórico-metodológicos das disciplinas envolvidas, 
possibilitando aos alunos experiências que integrem os diferentes enfoques, enriquecendo assim a compreensão acerca da realidade concreta, propiciando formas de ações autônomas e criativas. Salienta-se, dessa forma, que para o desenvolvimento de uma prática interdisciplinar, é necessário que o professor tenha uma visão global do objeto de conhecimento de sua disciplina, para criar elos com as outras que fazem parte do quadro curricular do contexto escolar. O professor necessita ter consciência do sentido de sua disciplina para que possa entendê-la e, a partir disso, manter vínculos com a realidade concreta do mundo contemporâneo.

De acordo com Fazenda (1994), o trabalho que emprega a metodologia interdisciplinar parte de uma liberdade científica, alicerça-se no diálogo e na colaboração, funda-se no desejo de inovar, de criar, de ir além e, exercita-se na arte de pesquisar. Ou seja, não objetiva apenas uma valorização técnico-produtiva ou material, mas, sobretudo, possibilitando uma ascese humana, na qual se desenvolva a capacidade criativa de transformar a realidade concreta e histórica numa aquisição maior de educação em seu sentido lato, humanizante e libertador do próprio sentido do ser-no-mundo. É relevante destacar que a interdisciplinaridade supõe um eixo integrador entre as disciplinas do currículo escolar, para que os educandos aprendam a olhar um mesmo objeto sob diferentes ângulos e perspectivas.

\section{A DESMOTIVAÇÃO: DO PROFESSOR E DO ALUNO}

Tendo em vista que a desmotivação constitui-se num problema de difícil resolução é essencial que o educador compreenda o que é "motivação" como ela se constrói e se caracteriza, especialmente, no ambiente da escola. Geralmente, a falta de motivação tem origem nas características individuais do educando e do espaço escolar como um todo, o que gera no estudante o medo do seu próprio fracasso escolar, bem como o temor de não saber lidar com situações que fogem às suas expectativas como aluno e às da sua família.

De acordo com Vernon (1973), a motivação é considerada uma espécie de força interna que emerge, regula e sustenta todas as ações mais importantes do ser humano. A motivação consiste numa experiência interna muito difícil de ser analisada e compreendida de forma direta. Ou seja, a motivação representa uma força de difícil especificação da sua natureza, por ser uma experiência interna, portanto, não pode ser observada diretamente, a não ser pelos comportamentos evidenciados pelos sujeitos.

Nesse sentido Bzuneck (2004, p. 9), indica que:

A motivação tem sido entendida ora como um fator psicológico, ou conjunto de fatores, ora como um processo. Existe um consenso generalizado entre os autores quanto à dinâmica desses fatores psicológicos ou do processo, em qualquer atividade humana. Eles levam a uma escolha, instigam, fazem iniciar um comportamento direcionado a um objetivo.

Para Vernon (1973), uma das maneiras mais adequadas para o estudo da "motivação" são aquelas que se valem de critérios subjetivos. O autor entende que são estes os principais elementos de que se dispõe para avançar no aprofundamento dos estudos acerca da motivação humana, sendo que eles se relacionam com a bagagem que cada sujeito traz em sua individualidade, constituindo-se na força motriz que possibilita a realização de alguma ação. Nesse encadeamento, pode-se dizer que as teorias produzidas sobre motivação têm como base a busca 
pelo entendimento das singularidades do ser humano, ou seja, se não há pré-disposição do indivíduo à motivação, será difícil motivar aquele que não deseja.

Desse modo, o estudo da motivação, mais especificamente voltado para o campo escolar, passa a ser parte integrante da vida dos educandos no momento em que estes se inserem na escola. As atividades de estudos representam a oportunidade e uma das fontes com as quais cada aluno conta para atender não somente às expectativas mais concretas, mas, também, aquelas menos observáveis que se situam no campo das necessidades psicológicas. Desse modo, será que o trabalho escolar, para o estudante tem a mesma relevância que o educador atribui às suas próprias expectativas? Entende-se que um trabalho inadequado e/ou precarizado, também produz um resultado final, um estado interior que pode gerar no indivíduo desapontamentos e/ou frustrações, as quais desmotivam à busca e ao envolvimento no processo ensino-aprendizagem. De certo modo, isso explica, além do estado interior que tipifica a insatisfação em relação às solicitações da vida de estudante no cotidiano escolar; também pode acelerar o processo de estagnação na trajetória estudantil e, consequentemente, na busca por uma formação profissional adequada.

No ambiente escolar, determinados alunos apresentam dificuldades em interagir na execução de certas atividades, outros apresentam resistência no sentido de interagir na construção do seu próprio conhecimento, isolando-se dos demais colegas e dos professores, negando-se a participar das atividades indicadas, não apresentando interesse em realizar as proposições referentes à aprendizagem. Diante disso, é preciso refletir se essa desmotivação que consome o estudante ocorre devido ao próprio trabalho escolar que se realiza em sala de aula; sendo isso é necessário que o docente arranje novas estratégias de abordagens, novas perspectivas, novas formas de organização para inovar a prática pedagógica. Conforme Sartori e Segat (2007, p. 81), "a cada nova situação vivenciada é preciso construir alternativas metodológicas que possibilitem a interação com o educando de forma dialógica, problematizadora, colaborativa, prazerosa, desafiadora".

Entretanto, essa desmotivação dos alunos pode ter sua causa na falta de motivação do próprio professor. Ou seja, pode até ser consequência da relação professor-aluno. Entende-se que o professor desmotivado não toma atitudes que levem o educando a iniciativas criativas e inovadoras no contexto escolar. Geralmente, o professor espera por soluções prontas, receitas milagrosas, que brotem de instâncias superiores ou de algum "iluminado", não compreendendo que é de sua competência buscar novos recursos pedagógicos e metodológicos, que possam estimular os alunos em seus aprendizados.

Quando um professor se encontra pouco motivado ou estimulado, é sintoma de que não acredita em seu potencial de educador, dessa maneira, acaba produzindo aquém do que sua capacidade permite, deixando de aproveitar os recursos que têm em mãos ou os que lhes são oferecidos pela escola. O professor não pode esquecer de que ele é essencial como formador de cidadãos para o contexto da sociedade em permanente mudança. Também, é necessário que ele creia no valor de sua profissão, que seu propósito precisa ir além da missão de passar conteúdos didáticos, desenvolvendo autoestima, motivando e motivando-se, transmitindo aos alunos empolgação, tendo mais paixão pelo que faz.

A relação entre professor e aluno é muito intensa, considerando-se a convivência diária que acontece em períodos constantes e contínuos. Em razão disso, se não houver um envolvimento afetivo a desmotivação pode surgir, comprometendo o interesse do aluno pelo ambiente, pela vivência e pelos conteúdos estudados em sala de aula. Acredita-se que é no afeto 
que se estabelece a confiança, o respeito mútuo, criando um ambiente favorável para a aprendizagem e para a convivência social. $\mathrm{Na}$ motivação do aluno está intrínseco o relacionamento interpessoal com o professor, o qual necessita ser respeitoso, mas não permissivo; firme, mas não rude e, por meio dele, conseguir perceber as dificuldades e as potencialidades do aluno, agindo de forma que o estimule a superá-las ou a desenvolvê-las, respectivamente. Portanto, é preciso ter em conta que o comportamento humano é essencialmente complexo, por isso, há necessidade do apoio dos estudos da Psicologia para melhor compreender as circunstâncias dos "ditos" comportamentos complexos.

No que se refere à prática do professor, esta pode se tornar um fator de desmotivação, pois, se o professor trabalhar uma aula sem diálogo, sem problematização, deixando para o aluno a tarefa de apenas anotar, memorizar e devolver, isso, certamente desmotivará os alunos. Geralmente, o aluno gosta de dinâmicas diferentes nas aulas, conteúdos novos e, principalmente, que o educador interaja com a turma. Todavia, a tarefa do professor não consiste apenas em contemplar a subjetividade do educando, mas acima de tudo compreender como o educando constrói a sua subjetividade, isto é, entender como são internalizados os padrões de comportamento, sobre os quais se infere a existência de algum motivo, de uma força propulsora ou de um desejo.

No entender de Sartori e Segat (2007), baseados em Freire, asseguram que é fundamental que cada educador possa se sentir estimulado e desafiado ao longo de sua atuação profissional a reelaborar a sua prática, ressignificando seus saberes, principalmente aqueles que constituem sua prática pedagógica. Sendo assim, a motivação necessita servir de estímulo ao sujeito, a fim de que ele possa sanar suas necessidades e seus desejos, provocando comportamentos que promovam a concretização de suas metas pessoais em relação ao seu desenvolvimento cognitivo.

\section{PRESSUPOSTOS DO PROCESSO ENSINO-APRENDIZAGEM}

A análise dos diferentes conceitos que se enlaçam no processo ensino-aprendizagem necessita ter no horizonte a diversidade de épocas nas quais estes se desenvolveram, bem como compreender as mudanças geradas no decorrer da trajetória da produção dos saberes pelo ser humano. É necessário, também, relembrar que o processo ensino-aprendizagem acontece a todo o instante e, em qualquer lugar e/ou espaço. Diante dessa premissa, questiona-se: Qual o papel da escola em relação à efetivação do processo ensino-aprendizagem? Como a escola deve proceder? Que papel tem o professor? Não cabe aqui responder aos questionamentos, mas indicar que a função da escola na perspectiva da teoria crítica é a de realizar a mediação entre os saberes prévios do educando e o conhecimento produzido e sistematizado historicamente, possibilitando algumas alternativas para o acesso ao conhecimento científico.

Dessa maneira, entende-se que os estudantes caminham na busca da apropriação do conhecimento sistematizado, com vistas a transformar as informações e os saberes de senso comum em conhecimentos que estejam balizados pela ciência, desenvolvendo seu pensamento no horizonte da formação de novos conceitos. O processo ensino-aprendizagem, desse modo, necessita favorecer o educando no sentido de que se aproprie dos conteúdos curriculares no decurso da atividade realizada com o propósito da construção de conhecimentos. 
O conceito de aprendizagem é um conceito prévio, um requisito indispensável para qualquer elaboração teórica sobre o ensino. No entanto, a teoria e a prática didáticas necessitam de um corpo de conhecimentos sobre os processos de aprendizagem que cumpra as condições fundamentais como abranger, de forma integral e com tendência holística, as diferentes manifestações, processos e tipos de aprendizagem.

O processo ensino-aprendizagem ocorre na interação entre professor e aluno, aluno e aluno e destes com o mundo. A ação humana é sempre precedida por uma antecipação mental do que se pretende realizar, o que demonstra a importância da teoria, embora, muitas vezes, isso passe despercebido pela maioria dos docentes. A aprendizagem humana, dessa forma, relacionase com a educação e com o desenvolvimento de cada ser humano. Por isso, precisa ser orientada no sentido de que o sujeito esteja motivado para aprender, daí a importância do professor auxiliar no estabelecimento de novas relações entre o aluno e o meio em que se insere.

A educação tem o objetivo transmitir às novas gerações, os saberes necessários para a vida em sociedade e, por isso, não é um fenômeno único, que ocorre de forma igual em todos os lugares e em todas as épocas. Em cada período histórico e conforme a situação específica de cada sociedade, a educação ora é sistematizada com a própria vida; no período pré-histórico, nas sociedades tradicionais contemporâneas ou nos grupos indígenas pouco aculturadas, ora mais sistematizadas, como na Grécia e em Roma, ou na sociedade capitalista contemporânea (MELO, 2011).

Para Piaget (1973), o desenvolvimento explica a aprendizagem, não o inverso. Para entender o que ele quer dizer, deve-se começar pela compreensão do que é aprendizagem. Nessa perspectiva, Piaget (1973) distingue duas espécies de aprendizagem: em sentido lato e em sentido stricto. A aprendizagem em sentido stricto está relacionada a uma situação específica, uma experiência, um treino, levando a um conhecimento limitado, restrito àquele conteúdo. Esse tipo de aprendizagem tende a enfatizar os aspectos figurativos do pensamento e permite o conhecimento de estados, não de transformações. Já a aprendizagem em sentido lato confundese com o próprio desenvolvimento, está relacionada aos aspectos operativos e explicam o processo de transformação que conduz a um dado conhecimento.

Vygotsky (1998) em seus estudos sobre a aprendizagem toma como foco o fundamento sócio-histórico no horizonte marxista, enfatizando a relevância das interações entre sujeito e objeto, tornando explicito que a ação do sujeito sobre o objeto está enlaçada ao processo de mediação social. Portanto, na perspectiva vygotskyana, existe o entendimento de que a criança é um ser ativo, mas, sobretudo, interativo, podendo-se daí inferir que o conhecimento consiste numa construção social, que se expressa em forma da produção de saberes culturais e sociais, promovendo interfaces com as manifestações da própria sociedade.

Para Vygotsky (1998), a zona de desenvolvimento proximal ou potencial (ZDP) representa a distância entre o nível de desenvolvimento potencial, ou seja, aquilo que o sujeito consegue realizar com a ajuda de outros, e o nível de desenvolvimento real, isto é, aquilo que o indivíduo pode realizar sozinho, o que já possui em termos de desenvolvimento. Há muitas ZDPs em cada indivíduo, as quais são relativas às diferentes áreas do nosso conhecimento. Por exemplo: o nível de desenvolvimento real em história. É preciso conhecer esse nível nos alunos para poder intervir e para fazer avançar além daquilo que o sujeito conhece.

A mediação na ZDP contribui para o avanço no conhecimento. Se o investimento estiver no nível de desenvolvimento real, não haverá evolução; se, por outro lado, for muito acima deste, mesmo com a ajuda do outro não haverá avanço. Para investir na ZDP, é preciso investir em 
problemas que podem ser considerados, nem muito difíceis, nem muito fáceis para o educando, isto é, que seja algo que a criança, com a ajuda do professor ou de algum colega mais experiente, consiga resolver.

Ao professor compete atuar na ZDP do aluno para que se torne real o que, primeiro é potencial, uma vez que só é possível a imitação daquelas ações que estão na ZDP. A criança não consegue imitar tudo, somente àquilo que se encontra na ZDP. De acordo com Vygotsky (1998, p. 126):

$\mathrm{O}$ aprendizado geralmente precede o desenvolvimento. A criança adquire certos hábitos e habilidades numa área específica, antes de aprender a aplicá-los conscientemente e deliberadamente. Nunca há um paralelismo completo entre o curso do aprendizado e o desenvolvimento das funções correspondentes.

O aprendizado na escola induz ao pensamento generalizante, pelo fato de se trabalhar com conceitos científicos. Nesse sentido, a manifestação de compreensão e de afetividade por parte do professor, pode constituir-se no fundamento de sua prática pedagógica e da eficácia no ato de aprender por parte da criança. A escola tem, por sua vez, um papel decisivo na promoção da evolução da consciência da criança e do desenvolvimento de seus processos mentais superiores. Portanto, a consciência reflexiva surge por meio do conhecimento científico, o qual deve ser produzido na interação do sujeito com o meio, compreendendo-o e analisando-o.

Ainda, conforme Vygotsky (1998), a sistematização própria dos conceitos científicos estrutura-se na mente da criança e depois é transferida para os conceitos cotidianos, modificando a sua estrutura psicológica. O processo de desenvolvimento define-se, assim, como a apropriação ativa do conhecimento disponível na sociedade da qual a criança faz parte. A apropriação que a criança faz do real depende de como este lhes é apresentado; como as pessoas que organizam o real direcionam a sua percepção; como chamam a atenção ou desconsideram certos aspectos. $O$ desenvolvimento da criança depende da apropriação que ela faz da experiência social, das regulações realizadas por outros, para a autorregulação.

O ensino não pode ser direcionado para o que a criança, o adolescente ou o adulto já sabe. Necessita, pois, antecipar-se ao desenvolvimento. O educador precisa provocar o desenvolvimento por meio do conhecimento científico. Para Vygotsky (1998), há uma relação complexa e dinâmica entre aprendizagem e desenvolvimento, que não se reduz a um vínculo linear entre esses dois processos. Dependendo de sua complexidade, há aprendizagens que incidem muito (aprendizagem da aritmética e da língua escrita) e outras que incidem pouco sobre o desenvolvimento psicológico (andar de bicicleta, escrever à máquina).

Para Vygotsky (1998), a aprendizagem gera desenvolvimento. Cabe ao educador intervir na ZDP, no espaço compreendido entre o que a criança já sabe fazer e o que só conseguiria realizar com o auxílio de uma pessoa experiente ou adulta, para provocar avanços no seu desenvolvimento. A internalização de formas culturais de comportamento está relacionada à reconstrução, o que ocorre por meio das operações mentais superiores em relação aos signos.

\section{DESCREVENDO O MATERIAL EMPÍRICO}


Os dados foram coletados por meio de um questionário direcionado aos alunos e professores do Ensino Fundamental noturno, numa Escola Estadual da periferia do município de São Gabriel, a qual atende aproximadamente seiscentos (600) alunos distribuídos em três (3) turnos e que abrange seis (6) bairros de moradores com baixo poder aquisitivo, com um número grande de famílias chefiadas por mulheres; há elevado número de ocorrências policiais, as quais envolvem vários moradores da região. Os dados buscaram pela constatação da influência da desmotivação no ato de ensinar e de aprender. Fato este que ocorre em diferentes níveis de ensino e com os pertencentes profissionais a todas as áreas da educação formal.

\section{O SEGMENTO PROFESSOR}

Os procedimentos da pesquisa, já mencionados, permitiram traçar um quadro das características mais gerais dos professores questionados no Ensino Fundamental noturno, bem como registrar as expectativas e representações sociais sobre o estudo em questão. $O$ ensino noturno apresenta atores (alunos e professores) que fazem parte de um contexto escolar contemporâneo e da conjuntura atual das escolas. Para este estudo foram distribuídos questionários para vinte (20) professores, somente doze (12) responderam, um total de sessenta por cento (60\%). Quanto aos alunos, manteve-se a mesma porcentagem, sendo que cinqüenta (50) receberam o instrumento e somente trinta e um (31) responderam $60 \%$ do total.

Os educadores do ensino noturno têm formação específica na área em que atuam (58\%); o tempo de exercício na docência fica entre 20 a 30 anos; faixa etária entre 40 a 60 anos; não recebem outro tipo de remuneração. São profissionais da educação que exercem a profissão durante o dia, com jornadas de trabalho de 22 horas semanais (regimento do Município), ou trabalhando 40 até 60 horas semanais, considerando que os índices salariais não são coerentes com o trabalho realizado. Quando chegam à escola, à noite, já estão, em muitos casos, no seu terceiro turno de trabalho diário. Encontram-se, portanto, cansados, pois enfrentam classes numerosas e heterogêneas, que evidenciam problemas de indisciplina, dificuldades de aprendizagem, além da infraestrutura das escolas não ser das melhores.

Também pode-se considerar como dificuldade vivenciada pelos professores os aspectos relacionados aos conteúdos, pois os mesmos conteúdos são trabalhados, tanto no turno diurno como no noturno. Não se faz uma análise das necessidades e dos interesses dos alunos que frequentam o ensino noturno para estruturação do curso, do currículo escolar, sem considerar que as demandas dos alunos do noturno são diferentes daqueles do diurno, assim, a forma de trabalhar os conteúdos também precisa ser diferente.

Os professores entendem que a metodologia empregada por eles necessita perpassar a seleção de conteúdos, pois precisa ser precedida pela justificativa da sua escolha. Uma atenção especial precisa ser dada ao preparo das aulas, ao como desenvolver os conteúdos em sala de aula. Ainda, a avaliação necessita desenvolver-se num processo contínuo, considerando os procedimentos, tais como; técnicas, recursos, interações, atividades em classe, extraclasse, pois, estas, por sua vez, aprofundam o sentido da aula do professor. São considerações que necessitam ser realizadas para evitar que o aluno, que já vem desmotivado, perca ainda mais o interesse pela aula. Outro fator importante a ser levado em consideração é o registro do que ocorre em aula para que os momentos pedagógicos não sejam apenas fatos isolados, mas constituam os elos de uma corrente que possibilita a construção contínua do conhecimento. 
Pela análise dos dados coletados, a desmotivação dos alunos e professores, frente ao ensino noturno consiste na falta de tempo, ou até mesmo no desconhecimento das atividades dos alunos e de suas expectativas. Os conteúdos são trabalhados da mesma forma no ensino diurno e noturno, embora os professores afirmem trabalhar interdisciplinarmente, a realidade mostra que a prática pedagógica não acontece dessa forma. O máximo que acontece é de os professores trabalharem de forma multidisciplinar. A forma de trabalhar acompanha o diurno, os exercícios seguem a mesma didática, são utilizados os mesmos livros didáticos, textos ou apostilas que pouco atende às necessidades dos estudantes. Isso, de certa maneira, provoca desinteresse e incentiva a conversas paralelas em sala de aula entre os alunos, não motivando para situações de aprendizagem significativa, por consequência, ocorre repetência e evasão.

Carvalho (1998, p. 80) faz um comentário bastante significativo quando diz que:

Até que ponto lecionar à noite significa o empenho em trabalhar para a construção da cidadania do aluno, para a explicitação da inter-relação entre o saber produzido na academia e o produzido na indústria, na oficina, na loja, na lavoura? É comum, no entanto, pela rotina já estabelecida das salas de aula, que nem o realmente acadêmico chegue até a sala de aula, há o refúgio dos livros didáticos, onde a simplificação atropela a compreensão dos conceitos.

A autora (1998, p. 81) continua ressaltando que "o desconhecimento, por parte dos professores, das situações cotidianas vividas pelos alunos do ensino noturno, deixa de estabelecer a ponte entre o conhecimento sistematizado da escola e o conhecimento do cotidiano impregnado do senso comum produzido pelo trabalho".

Os professores questionados asseguram que muitas são as resistências demonstradas pelos alunos em relação aos conteúdos ministrados nas aulas do ensino noturno, o que acreditam eles, se constitui num dos principais motivos de desmotivação. Mesmo que se tenha a consciência de que necessitam ser trabalhados de forma mais integrada, torna-se inviável por falta de tempo para os professores reunirem-se e construírem seu planejamento coletivamente. A despeito disso, os professores, na maioria das vezes são taxados como os culpados pelo fracasso do aluno, pela evasão e, principalmente, pela sua desmotivação. No entanto, os docentes também são vítimas da estrutura organizacional que inclui os cursos de ensino noturno, dentro da qual inevitavelmente devem realizar seu trabalho. E assim:

[...] ao enumerar as fragilidades que encontram no aluno trabalhador que tem, sob sua responsabilidade, nas condições de trabalho que dispõem para sua prática docente, no serviço, muitas vezes autoritário e omisso dos especialistas e do sistema de ensino dentro dos quais têm de se mover, os professores conduzem suas análises na direção também de sua própria fragilidade ante um problema complexo e de fortes implicações sociais ( $\mathrm{PUCCl}$, 1994, p. 185).

Nesse sentido, no ensino noturno $74 \%$ dos professores acreditam que para motivá-los é necessário trabalhar uma metodologia diferenciada. No entanto, $26 \%$ deles afirmam não ser necessário distinguir diurno de noturno, mas, admitem que é necessário mudar os procedimentos de ensino, proporcionando ao educando a oportunidade de vivenciar as diferenças metodológicas 
que permitam a inserção sociopolítica e cultural dos estudantes. A metodologia utilizada pelos professores deve englobar não somente a seleção de conteúdos, mas necessita ser precedida pela justificativa da escolha dos conteúdos a serem desenvolvidos. É necessário que preveja também o os recursos para o seu desenvolvimento em sala de aula, considerando a avaliação contínua dos procedimentos usados, tais como: técnicas, recursos, pesquisas, atividades extraclasse, etc.

\section{O SEGMENTO ALUNO}

Para que se tenha uma reflexão mais consistente, no ensino noturno é necessário conhecer quem e quantos são os alunos que freqüentam aulas à noite, bem como é preciso repensar a escola para atender as suas demandas. Por meio do questionamento aplicado para os alunos, constatou-se que, na sua maioria são jovens oriundos do ensino diurno que, após sucessivas repetências, ficam fora da idade, então, são encaminhados ao ensino noturno. Há também aqueles que estão inseridos no mercado de trabalho, com jornadas de oito ou mais horas diárias, em trabalhos legalizados ou autônomos sem qualificação. Essa situação revela que estes estão nesta condição por extrema necessidade de sobrevivência. $O$ aluno-trabalhador é a principal figura do ensino noturno.

De acordo com Pucci (1995, p. 31), talvez a característica mais marcante de um aluno do ensino noturno seja a "condição de trabalhador desqualificado e super-explorado ao peso de um salário vil e de uma insuportável jornada dupla de trabalho; a da fábrica, loja ou escritório, e a da escola noturna".

As respostas ao instrumento evidenciaram que os alunos vão para o ensino noturno por diversos motivos, seja para completar os estudos para uma futura qualificação profissional, seja para encontrar seu grupo social, ou para buscar algo melhor para a vida. O estudante busca algo que vai além das necessidades de informação e de formação para auxiliar no seu dia a dia, na luta pela sobrevivência, ele busca relações socioafetivas e condições para sentir-se pertencido. Eles querem oportunidades iguais para sentirem-se incluídos, o que se constitui num dos aspectos mais enfáticos na relação escola-aluno, pois, o aluno do noturno necessita de ensino contextualizado para se concretize as suas expectativas. No entanto, se a escola não lhes oferece esse "algo a mais" que ele busca, certamente, se sentirá desmotivado e impelido a abandoná-la.

O aluno no ensino noturno não é visto conforme suas características e especificidades, quando isso é feito ocorre de forma paternalista ou autoritária, na tentativa de justificar que há diferença de tratamento quanto à seleção de conteúdos, aos procedimentos metodológicos, a avaliação, a carga horária. Os argumentos no cotidiano da escola revestem-se de alguns prejulgamentos, enfatizando que o aluno vem cansado; ou não tem interesse ou, ainda, não tem responsabilidades (atrasos, faltas, desistências). Ainda, os professores citam que os alunos do turno noturno apresentam defasagens ou falta de base em conteúdos já estudados, que supostamente teriam sido aprendidos em momentos anteriores de sua escolarização.

Os alunos ao serem recebidos nas escolas noturnas, empregados ou não, encontram professores, que como os alunos vêm de uma segunda ou terceira jornada de trabalho, considerando as diferenças sociais existentes. Esses alunos são rotulados por uma série de preconceitos e relegados a serem atingidos por práticas pedagógicas desmotivadoras, mecânicas, que os fazem sentirem-se cada vez mais diferenciados socialmente.

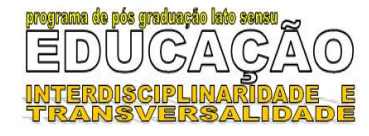


Como confirmação do que foi constatado na pesquisa descreve-se a fala de alguns alunos do ensino noturno:

Estudo a noite porque preciso trabalhar durante o dia para ajudar minha família.

Preciso trabalhar, hoje tudo está muito caro e todos têm que ganhar um pouco para ajudar nas despesas da casa.

Porque é o período que me coloquei, é o tempo que tenho para terminar o ensino fundamental.

Porque passei anos de bobeira, sem estudar, por isso, estudo à noite, na esperança de recuperar o tempo perdido, de melhorar de vida.

$\mathrm{Na}$ avaliação sobre a escola e as aulas, quanto a serem atrativas, $40 \%$ dos alunos respondentes do instrumento asseguraram que nem a escola e nem as aulas possuem algum tipo de atrativo. Isso significa que é urgente buscar algo para mudar essa realidade, principalmente na prática pedagógica e na revisão do currículo do ensino noturno.

\section{ALGUMAS CONSIDERAÇÕES SOBRE O ESTUDO}

Considerando que a escola necessita dar ao aluno, além de um universo singular de informações, o embasamento teórico-prático para que o sujeito possa ser um cidadão crítico, fazse necessário um exercício exaustivo para o aprimoramento do currículo escolar que garanta além do acesso do aluno à escola, a sua permanência e o seu sucesso. Não há dúvida de que deveríamos oferecer aos alunos aquilo que há de melhor e mais significativo no universo em que estamos inseridos. Para tanto, é necessário observar de onde parte o conhecimento, a partir dessa informação, escrever o currículo escolar para os cursos noturnos.

O conhecimento sugerido pelos currículos escolares prescreve a distinção de valores, de classes, de gênero, impondo, mesmo que disfarçadamente, a educação para a submissão de alguns e para o empoderamento de outros. Desse modo, cabe ao docente estimular os alunos para a descoberta, desafiando-os sempre a buscarem novos conhecimentos.

O fato é que a escola, hoje, não provoca suficientemente o aluno a assumir novos desafios de modo que se sinta motivado a construir novos conhecimentos. No entanto, atentos a tais sinais o professor precisa considerar que há alunos que apresentam dificuldades para interagir em certas atividades, há os que evidenciam resistência total ao fato de adquirir conhecimentos, isolando-se dos colegas, negando-se a participar das ações indicadas, não demonstrando interesse algum em realizar aquilo que se refere à aprendizagem.

O ensino noturno constitui-se numa ação educativa que é direcionada para um indivíduo de escolarização básica incompleta, ou nunca iniciada e que acorre aos bancos escolares na sua juventude ou já na idade adulta. No entanto, fazer um estudo sobre o ensino noturno nos leva a analisar todo um contexto de problemas sociais, pedagógicos e metodológicos que atingem essa modalidade de ensino. Pelas análises realizadas neste campo, observa-se que os alunos que estudam à noite assumem posturas de estudo que os diferenciam dos educandos do ensino 
diurno, pois seus objetivos enquanto cidadãos são singulares; são sujeitos que não conseguiram concluir seus estudos na "idade própria" e, na maioria das vezes, provêm de classes menos favorecidas social e culturalmente, os quais necessitam atuar no mercado de trabalho para obter condições de sobrevivência. Então, no sentido de auxiliar o educando desmotivado, o docente necessita preocupar-se com o espaço da escola, em especial o da sala de aula, também com a organização e o desenvolvimento das atividades, com a relação professor-aluno e com o processo de avaliação.

A LDB - Lei no 9394/96, prevê em seu artigo 4으, inciso VI; a oferta do ensino noturno regular, adequada às condições do educando, como comenta Caparalini (1991, p. 39): "O acesso do aluno noturno trabalhador à escola constitui um direito fundamental e um meio para facilitar a sua participação de maneira consciente e crítica na vida sócio-econômica-cultural e política da nação". Dessa forma, é assegurado a todos o direito à educação, independente de quais motivos os impediram de frequentar as escolas diurnas em "idade própria". No entanto, muitos questionamentos surgem no transcorrer do processo de implementação da escola noturna frente às exigências legais e as necessidades sociais. Nesse sentido, é preciso refletir sobre o aumento considerável das matrículas na educação básica, bem como acerca do ensino que, ainda, não está acompanhado da qualidade suficiente para atender as demandas socioeducacionais. Nisso estão imbricadas as divergências sobre os indicadores de qualidade do ensino, o que implica na necessidade da compreensão do papel da educação no processo de desenvolvimento da nação.

Através da literatura estudada, constatou-se que existem muitos problemas referentes ao ensino fundamental, principalmente pelas dificuldades que o permeiam, por isso, suas metas necessitam ser redefinidas e os objetivos voltados aos interesses das classes trabalhadoras, devendo repensar, também, os conteúdos e os métodos englobados nesse processo educativo, implicando numa série de decisões (CAPORALINI, 1991).

Os alunos que constituem as turmas do período noturno estão inseridos, na sua maioria, no mercado de trabalho, chegando à escola extenuados pela sua jornada de trabalho, o que resulta segundo Carvalho (1997, p. 10):

Num grande índice de evasão, reprovações, desistências, fato que contribui para a formação de um contingente de força de trabalho cada vez mais desqualificado, pois o que se aprende na escola nada tem a ver com o que se vive no mundo do capital.

Nesta linha de pensamento e de busca do conhecimento, Caporalini (1991, p. 41) comenta que:

O aluno da escola noturna busca numa sala de aula um pouco mais de educação, uma educação de boa qualidade, e que atenda aos seus interesses. Se o conteúdo desenvolvido, se a transmissão de conhecimentos não se processa de forma a lhes servir de instrumental para a vida, eles pode ser levado a abandoná-la.

O que mais se ouve no ensino noturno são professores reclamando de alunos que "não querem nada com nada", "que só querem mesmo é saber de conversar, de passar de ano, não interessando como e onde", existe uma verdadeira aversão pelo estudo, um conformismo, uma dificuldade de refletir sobre um texto e de elaborar questionamentos. Os alunos parecem que se negam totalmente a estudar. 
De um lado está o professor, o detentor do saber; de outro está o aluno, o receptor do saber, sem o questionamento de como se encontra o aspecto sócio-afetivo desse aluno. Quais as condições que determinaram a sua presença neste curso, nesta escola. Desse modo, o professor não consegue compreender porque o aluno age dessa maneira, como ele aprende, e o que precisa fazer para que possa motivá-lo, ajudando-o no processo de construção do conhecimento.

A metodologia pensada para as escolas noturnas apresenta, portanto, o poder social como fator determinante na produção e distribuição do conhecimento, na escolha dos conteúdos e estratégias, o que torna questionáveis nossas ideias e conviç̧ões sobre o que sejam as áreas centrais do conhecimento e as habilidades básicas para aprendizagem. A escola, porém, terá sempre na figura do professor a possibilidade concreta de articular conteúdos, ideias, objetivos e acontecimentos numa troca constante entre aprender e ensinar a partir de referenciais estruturados em conhecimentos, experiências e até em prescrições norteadoras.

Embora a educação brasileira esteja vivenciando um processo de plena democratização do ensino, pouco se ouve falar em permanência na escola, principalmente na escola noturna. Democratizar não significa apenas ofertar o acesso, pois há diversas problemáticas que fazem com que os alunos abandonem a escola, por exemplo, a necessidade de trabalhar, as condições precárias de estudo, os horários que não se adéquam às necessidades do educando, a falta de material didático, a metodologia de ensino inadequada. Ainda, há os que abandonam a escola, sobretudo, porque consideram que a formação escolar não é relevante, que não vale a pena enfrentar um sem número de obstáculos para permanecer ali, se quando terminam o curso, ou não conseguem emprego, ou quando conseguem se sentem despreparados para o desempenho de suas funções.

Mas, é importante esclarecer que a escola noturna é frequentada, também, por alunos não trabalhadores, por jovens, que na sua maioria não se enquadraram no perfil da escola diurna, ferindo o seu "modelo" de educação, resultando numa retenção altíssima, fazendo com que estes educandos frequentem a escola noturna. Esses jovens chegam à escola com ideias mais amplas do que simples convivência escolar; procuram lugar de socialização, de troca de experiências, tentando transformar espaços estruturados com horários fixos em momentos de descontração, em que poderão encontrar amigos e colegas.

A relação do ensino noturno e da desmotivação sugere uma nova abordagem metodológica, em que se possa refletir o ensino mediante novas exigências para a educação formal, bem como pensar sobre a relevância do ensino noturno e do processo da democratização da educação brasileira, a qual vem sendo debatida nas relações entre acesso e permanência dos alunos da educação básica, em especial, os da escola noturna. O estudo bibliográfico mostra que as pesquisas sobre o ensino fundamental regular noturno não são bastante recentes. Contudo, novas pesquisas poderão situar as características desse turno nos dias atuais, podendo conter diferenças e/ou manter as semelhanças.

\section{REFERÊNCIAS BIBLIOGRÁFICAS}

BRASIL. Lei de Diretrizes e Bases da Educação Nacional (Lei n. 9394/96), Brasília, 1996.

BZUNECK, J. A. A Motivação do aluno: aspectos introdutórios. Petrópolis: Vozes, 2004. CAPORALINI, M. Bernadete Santa Cecília. A transmissão do conhecimento e o ensino noturno. Campinas-SP: Papirus,1991.

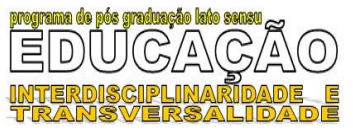


CARVALHO, C. P. Alternativas para o trabalho pedagógico voltado ao ensino noturno. São Paulo: FDE. 1998. p. 75-89 (Série idéia).

FAZENDA, Ivani C. Arantes. Interdisciplinaridade: História, teoria e pesquisa. Campinas, São Paulo: Papirus, 1994. (Coleção Magistério: Formação e trabalho pedagógico).

JAPIASSU, Hilton. Interdisciplinaridade e Patologia do saber. Rio de Janeiro: Imago, 1976.

MELO, Alessandro de. Fundamentos socioculturais da educação. Curitiba: Ibpex, 2011.

PIAGET, J. A epistemologia genética. Petrópolis: Vozes, 1973.

PUCCI, B. OLIVEIRA, N. R; SGUSSARDI. V. O ensino noturno e os trabalhadores. São Paulo:

Edufscar, 1994.

RUIZ, João Álvaro. Metodologia científica: guia para eficiência nos estudos. 3. ed. São Paulo: Atlas, 1991.

SARTORI, Jerônimo; SEGAT, Taciana Camera. Primeiros exercícios docentes: limites e desafios do estágio. SARTORI, Jerônimo; WESCHENFELDER, Lorita Maria (org.). Práticas Pedagógicas: Vivências e reflexões. Passo Fundo: Ed. Universidade de Passo Fundo, 2007. p. 78-100.

VERNON, M. D. Motivação Humana. Trad. L. C. Lucchetti. Petrópolis: Vozes, 1973.

VYGOTSKY, L. S. Pensamento e linguagem. São Paulo: Martins Fontes, 1998. 